\title{
BIOCHEMICAL EVALUATION OF LIVER FUNCTIONS IN DENGUE PATIENTS
}

\author{
Indira Bhaskar Biswas ${ }^{1}$, Sandip Ghosh², Nibedita Basu³, Chittaranjan Maity4 \\ 1 Professor, Department of Biochemistry, KPC Medical College \& Hospital, Kolkata. \\ ${ }^{2}$ Assistant Professor, Department of Biochemistry, KPC Medical College \& Hospital, Kolkata. \\ 3 Professor, Department of Biochemistry, KPC Medical College \& Hospital, Kolkata. \\ 4 Professor, Department of Biochemistry, KPC Medical College \& Hospital, Kolkata.
}

\section{ABSTRACT}

\section{BACKGROUND}

Dengue fever is a self-limited, systemic viral infection transmitted between humans by mosquito. It is a global health problem.

\section{MATERIAL AND METHODS}

In our study, liver functions were assayed in dengue patients admitted in KPC Medical College and Hospital. All the patients were selected randomly irrespective of age and sex. The diagnosis was established by clinical signs and symptoms, blood platelet count and serological tests such as NS1 antigen (ELISA), and IgM level (MAC-ELISA).

\section{RESULT}

Out of 98 patients, 6 had dengue haemorrhagic fever. 82 patients had enlarged liver of about $<2 \mathrm{~cm}$. In all cases, platelet count was low, NS1 was reactive and IGM was high. Liver enzymes such as Alanine transferase (ALT), Aspartate transferase (AST), Alkaline Phosphatase (ALP) were increased. Serum Protein levels (Total Protein), Albumin, globulin were less than normal level and A:G was altered, whereas serum bilirubin level there was no significant change. After seven days when there was complete recovery and the patient was waiting to be discharged, the parameters were repeated and it was found that the values were 2 to 3 times more than the normal.

\section{CONCLUSION}

It was concluded that in dengue patients, liver was affected. Besides that in few patients particularly in dengue haemorrhagic fever, Prothrombin time and Prothrombin level and platelet counts were also correlated.

\section{KEYWORDS}

Dengue, Hepatic Functions, Liver Enzymes.

HOW TO CITE THIS ARTICLE: Biswas IB, Ghosh S, Basu N, et al. Biochemical evaluation of liver functions in dengue patients. J. Evolution Med. Dent. Sci. 2016;5(73):5331-5334, DOI: 10.14260/jemds/2016/1209

\section{INTRODUCTION}

Dengue fever also known as break bone fever is an infectious tropical disease caused by dengue virus. Dengue is now a global threat and is endemic or epidemic in almost every country located in tropical and subtropical areas. Incidence of dengue has grown dramatically around the world in recent decades. A recent estimate indicates 390 million dengue infection per year ( $95 \%$ credible interval 284-528 million) of which 96 million $(95 \%$ credible interval $67-136$ million)manifest clinically. ${ }^{1}$ Existence of dengue like disease was reported in 1779 when an epidemic swept Asia, Africa and North America.[2] In India, DENV (dengue virus) was isolated in 1946 and many outbreaks were reported.[3] Dengue haemorrhagic fever was first reported in Kolkata, West Bengal in 1963.[4] The rapidly expanding global foot print of dengue is a public health challenge with an economic burden that is currently unmet by licensed vaccines, specific therapeutic agents or efficient vector control.

Financial or Other, Competing Interest: None.

Submission 01-08-2016, Peer Review 27-08-2016,

Acceptance 02-09-2016, Published 10-09-2016.

Corresponding Author:

Dr. Indira Bhaskar Biswas,

Professor,

Department of Biochemistry,

KPC Medical College \& Hospital, Kolkata.

E-mail: indu170@rediffmail.com

DOI: $10.14260 /$ jemds $/ 2016 / 1209$
Incidence of dengue has increased due to urbanisation, population growth, increased international travel, global warming.

Dengue fever is caused by RNA flavivirus transmitted to people through the bite of a female Aedes aegypti mosquito. Infection with dengue virus can be present in mild form as classic dengue fever or more severe form of disease: the dengue haemorrhagic fever (DHF) and dengue shock syndrome (DSS). Dengue virus an arbovirus, circulates as four distinct serological types DENV-1,2,3,4. Contracting one form of dengue fever provides lifelong immunity from that serotype but not from other serotypes. If a person is infected a second time by a different strain, the antibodies from the first attack can only partially bind to the virus and are unable to prevent infection. The antibodies with the virus loosely attached then shuttles into an immune cell would normally kill the virus, but because the virus is not properly attached it breaks free once it gains entry to the human immune cell where it replicates into more viral particles and thereby enhancing the infection. ${ }^{5}$ Some evidence has suggested that there is greater involvement of liver infection with DENV-2 compared to other 3 serotypes. Monotypic infection with DENV-1 was 9.5\%; with DENV-2 $60.8 \%$ and with DENV-3 was $29.7 \% .{ }^{[6]}$ A study carried out in Brazil showed that DENV-3 was isolated in more number of cases than DENV-2 in the classic form of the disease. ${ }^{[7]}$

Diagnosis of dengue is based on the findings of fever plus two of the following symptoms: rash, generalised pain, nausea, vomiting, low WBC count, positive tourniquet test or any warning signs like abdominal pain, mucosal bleeding, 
increased haematocrit with low platelets, lethargy and liver enlargement in someone who lives in endemic area.[8] Decreased level of consciousness occurs in $0.5-6 \%$ of severe cases which is attributed either to infection of the brain by the virus or indirectly as a result of impairment of vital organs, for example the liver.[9]

Liver involvement is universally present in children and in adult patients with dengue infection (DI).[10] Hepatocytes are the site of dengue virus replication and hence the involvement of liver in dengue disease.[11] Liver damage is a common complication of dengue infection and aminotransferase levels are a valuable marker for monitoring dengue cases. ${ }^{[7]}$

The present study is aimed to evaluate the hepatic functions in DENV patients who were seen in Kali Pradip Chaudhuri Medical College Hospital, Kolkata.

\section{MATERIALS AND METHODS}

A prospective study of 98 patients diagnosed and treated at our institute during an outbreak of dengue infection in Kolkata. Patients were selected randomly irrespective of all age group and both sex. All clinically suspected DVI patients as per WHO guidelines criteria were screened and the probable diagnosis was based on 2 or more of the symptoms with high fever, a detailed clinical examination, serological and haematological tests were conducted to confirm the diagnosis of DVI. And in DHF patients who presented with high fever of sudden onset, retro-orbital pain, arthralgia, generalised malaise, bleeding particularly in skin (Petechiae), occasionally in gums and nose, melena and low blood pressure were included. Patients diagnosed with malaria, enteric fever, hepatitis by relevant investigations were excluded.

\section{SEROLOGY}

Test for the detection of anti-dengue Abs were carried out in serum samples collected after $5^{\text {th }}$ day $-10^{\text {th }}$ day following the onset of symptoms. Viraemia in dengue lasts for less than 5 days and that IgM antibody response takes 5-10 days to develop in cases of primary dengue viral infection and 4-5 days in case of secondary dengue virus infection. ${ }^{[8]}$ MAC-ELISA \& NS1 Antigen tests were conducted in accordance with the manufacturer's instructions. When results were positive, patients were considered to be currently infected with Dengue virus. Platelet count and haematocrit also supported the diagnosis of Dengue virus. Liver enzymes such as ALT (Alanine aminotransferase), AST (Aspartate aminotransferase), ALP (Alkaline Phosphatase), Serum protein levels-Total proteins, Albumin, Globulin, A: G, Serum Bilirubin levels were measured on the day of admission (on the $5^{\text {th }}$ day after the onset of symptoms) and also the tests were repeated before the patient was fit to be discharged from hospital.

\section{Analysis of Liver Function Tests}

AST, ALT, Total Protein, ALP was analysed by Autoanalyser Mindray BS-390. Kit used was Shenzhen Mindray Bio-Medical Electronics Co. Ltd., China.

\section{Method for AST}

Aspartate aminotransferase kit \{International Federation of Clinical Chemistry (IFCC) \} without pyridoxal phosphate activation.

\section{Method for ALT}

Alanine aminotransferase kit \{(International Federation of Clinical Chemistry (IFCC) $\}$ without pyridoxal phosphate activation.

\section{Method for Alkaline Phosphatase}

IFCC and Laboratory medicine modified method. Dengue fever may be diagnosed by Virus isolation in cell culture, nucleic acid detection by PCR, viral antigen detection or specific antibodies (serology).[12] PCR and Viral antigens detection are more accurate in the first 7 days, not widely available due to their greater cost.[13] Tests for dengue-virus specific Abs, types IgM \&IgG can be useful in confirming a diagnosis in later stages of infection. In a person with symptoms, the detection of IgM is considered diagnostic.[14]

\section{RESULTS}

The prospective study is an attempt to elucidate the clinical profile and laboratory findings of dengue infected patients seen in our hospital. 92 patients (94\%) presenting with classic dengue features and $6(6 \%)$ were DHF; 3 of these patients went into DSS. Out of 98 patients, 41 were males and 57 females. Aged between 09 to 65 years with majority of cases ranging between 10-19 yrs. Adults were 83 and Children 15. The common clinical symptoms by the dengue patients were fever, headache, GI symptoms is shown in fig 1 . The routine lab investigations done in patients with DVI are shown in the Table 1. Laboratory parameters in patients with dengue viral infection is shown in Table 2. Serological tests showed 81\% NS1 reactive and 100\% IgM reactive and 7\% showed IgM \& IgG positive. Liver function tests showed increased levels of aminotransferases in all our 98 cases (Table -3). Total protein was $<6 \mathrm{~g} \%$ in $(74 \%)$ and Albumin $<3.5$ and A:G ratio was $<1$. But the Serum bilirubin level was within normal limits.

When the presenting symptoms had subsided, the tests were repeated and we found aminotransferase levels did not come to normal levels.

\section{STATISTICS}

Median values for all groups and both Median and Mean values for DHF groups. 95\% Confidence Interval (CI) of median for the selected parameters of Dengue cases have been determined along with $95 \% \mathrm{CI}$ of mean values of the parameter in DHF to understand the range of $95 \% \mathrm{CI}$. For DF, Median has been used as a representative average along with its $95 \%$ CI. Median was used because fluctuation is less, more appropriate for large sample $>30$ regarded. For DHF $n=6$. Thus, for small number of values of the parameter mean being better representative average has been used along with $95 \% \mathrm{CI}$.

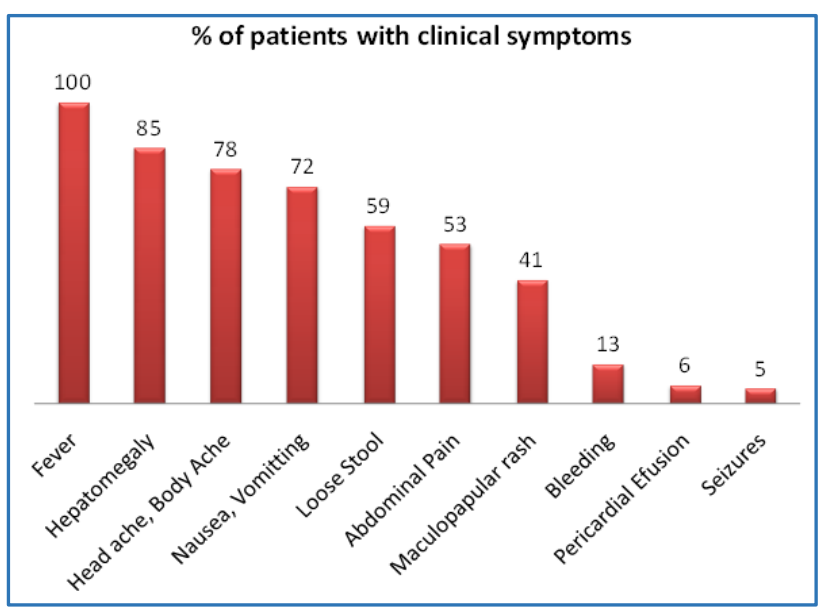

Fig. 1: Percentage of Dengue patients with Clinical Symptoms 


\begin{tabular}{|c|c|}
\hline Parameter & Values \\
\hline Haemoglobin & $<10.5 \mathrm{~g} / \mathrm{dL}(37 \%)$ \\
\hline Platelet count & $<100,000 / \mathrm{cu} . \mathrm{mm}(87 \%)$ \\
& $<50,000 / \mathrm{cu} . \mathrm{mm}(13 \%)$ \\
\hline White Blood Cells & $<3000 / \mathrm{cu} . \mathrm{mm}(24 \%)$ \\
\hline Prothrombin time & $>17$ seconds $(27 \%)$ \\
\hline Table 1: Laboratory Parameter in Patients with Dengue Viral Infection (n=98)
\end{tabular}

\begin{tabular}{|c|c|c|c|c|c|c|c|}
\hline & \multicolumn{3}{|c|}{ DF (n=92) } & \multicolumn{3}{c|}{ DHF (n=6) } \\
\hline $\begin{array}{c}\text { Liver } \\
\text { Enzymes }\end{array}$ & Median & $\begin{array}{c}\mathbf{9 5 \%} \text { CI of } \\
\text { Median < 200 }\end{array}$ & Median & $\begin{array}{c}\mathbf{9 5 \%} \text { CI of } \\
\text { Median <400 }\end{array}$ & Median & Mean & $\begin{array}{c}\mathbf{9 5 \%} \text { CI of } \\
\text { Mean >400 }\end{array}$ \\
\hline AST & 121 & $\begin{array}{c}\mathrm{n}=38 \\
115-172\end{array}$ & 309 & $\begin{array}{c}\mathrm{n}=54 \\
252-331\end{array}$ & 578 & 619 & $510-728$ \\
\hline ALT & 135 & $\begin{array}{c}\mathrm{n}=30 \\
102-161\end{array}$ & 322 & $\begin{array}{c}\mathrm{n}=62 \\
284-355\end{array}$ & 612 & 653 & $547-759$ \\
\hline ALP & 152 & $\begin{array}{c}\mathrm{n}=42 \\
130-188\end{array}$ & 297 & 1017 & 1033.5 & $988-1078$ \\
\hline \multicolumn{7}{|c|}{ Table 2: Comparison of Liver Enzymes between classic Dengue (DF) and DHF } \\
\hline
\end{tabular}

AST-aspartate transaminase, ALT-alanine transaminase, ALP-alkaline phosphatase.

\section{DISCUSSION}

The results of the present study showed that liver injury was present in almost all cases with dengue infection as indicated by the abnormal liver function tests and clinical manifestations of liver disease namely hepatomegaly, pain in the right hypochondrium, ascites and pedal oedema.

In our study, $85 \%$ patients had hepatomegaly which includes 15 children and 67 adults, 17\% had pedal oedema, $15 \%$ had ascites on clinical examination. Wahid SF et al has reported that in children, liver involvement is more profound in severe forms of DI such as DHF, DSS.[15]

Kuo et al reported that approximately $90 \%$ had abnormal AST, ALT, ALP, bilirubin and GGT.[16] Liver involvement occurred through an inflammatory process in parenchyma, provoked directly or indirectly by the virus, reducing the diameter of the lumen, biliary canaliculi causing obstruction. In our study, AST, ALT values were more than 5 times in classic dengue infection and ALP levels were also increased. And more than 10 times in DHF patients, bilirubin levels were within normal limits. The tests were repeated before discharge and it showed the enzyme values did not reach the normal limits.

In children, the aminotransferase levels were more than 10 times indicating children are at higher risk of hepatic involvement and possibility of developing hepatic encephalopathy.[17]

Hypoalbuminaemia in $74 \%$ and reduction of serum globulin may be an important factor of fluid loss into third space which is an indicative of severity of DVI.

None of our patients had jaundice, serum bilirubin levels were within normal limits, but $23 \%$ had itching.

Mechanism of liver injury in dengue may be due to direct effects of the virus or host immune response on liver cells, circulatory compromise, metabolic acidosis and hypoxia caused by hypotension or localised vascular leakage inside the liver.[10,18]

In our study, all our patients had two and more symptoms of DI. Liver profile showed increased values to support that there was liver involvement in DF and severe in DHF or DSS, but there were no deaths.

\section{CONCLUSION}

Hepatic dysfunction was observed in both classic dengue and severe forms DHF and DSS. Liver enzyme showed significant rise in children and also in adult. The abnormalities of liver function and degree of hepatic enlargement did not correlate. Even after 2 weeks, aminotransferase levels were much above the reference value. In geographical areas where dengue is endemic, patient presenting with high fever, tender hepatomegaly and increased liver enzyme levels, should be strongly considered as DI. To define the mechanism of liver injury in DI, further studies are required. Limitation of our study was ultrasound, and biopsy of liver was not done to confirm the diagnosis. Dengue haemorrhagic fever patients number are too small, it is hard to make conclusion difference of these two groups with these results.

\section{ACKNOWLEDGEMENT}

Professor BB Mukherjee, Dr. Aruna Bhushan for statistical analysis and Mrs. Jaya Chaturvedi for typing.

\section{REFERENCES}

1. Bhatt S, Gething PW, Brady OJ, et al. The global distribution and burden of dengue. Nature 2013;496(7446):504-7.

2. Gubler DJ. Dengue and dengue hemorrhagic fever. Clin Microbiol Rev 1998;11(3):480-96.

3. Balaya S, Paul SD, D'Lima LV, et al. Investigations on an outbreak of dengue in Delhi in 1967. Indian Journal of Medical Research 1969;57(4):767-74.

4. Aikat BK, Konar NR, Banerjee G. Haemorrhagic fever in Calcutta area. Indian Journal of Medical Research 1964;52:660-75.

5. Kate Wighton. Dengue virus exposure may amplify Zika infection. Imperial college London news 2016.

6. Seneviratne SL, Malavige GN, de Silva HJ. Pathogenesis of liver involvement during dengue viral infections. Transactions of the Royal Society of Tropical Medicine and Hygeine 2006;100(7):608-14. 
7. De Souza LJ, Nogueira RM, Soares LC, et al. The impact of dengue on liver function as evaluated by aminotransferase levels. Brazilian J Infect Dis 2007;11(4):407-10.

8. World Health Organization. Dengue \& dengue haemorrhagic fever diagnosis, treatment, prevention and control. 2nd edn. Geneva: World Health Organization Publishers 1997:10-15.

9. Gould EA, Solomon T. Pathogenic flaviviruses. The Lancet 2008;371(9611):500-9.

10. Mohan B, Patwari AK, Anand VK. Hepatic dysfunction in childhood dengue infection. J Trop Pediatr 2000;46 (1):40-3.

11. Duncan RS, Khakpoor A. Involvement of the liver in dengue infections. Dengue Bulletin 2009;33(1):75-86.

12. Guzman MG, Halstead SB, Artsob H, et al. Dengue: a continuing global threat. Nat Rev Microbiol 2010;8 (Suppl12):S7-16.
13. World Health Organization. Dengue guidelines for diagnosis, treatment, prevention and control. New Edition Geneva, Switzerland: World Health Organization 2009:90- 5 .

14. Gubler DJ. Dengue viruses. In : Mahy BW, Van Regenmortel MH, eds. Desk encyclopedia of human \& medical virology. Boston: Academic Press 2010:372-82.

15. Wahid SF, Sanusi S, Zawawi MM, et al. A comparison of the pattern of liver involvement in dengue haemorrhagic fever with classic dengue fever. Southeast Asian J Trop Med Public Health 2000;31(2):259-63.

16. Kuo CH, Tai DI, Chang-Chein CS. Liver biochemical tests and dengue fever. Am J Trop Med Hyg 1992;47(3):265-70.

17. Faridi MM, Aggarwal A, Kumar M, et al. Clinical \& biochemical profile of dengue haemorrhagic fever in children in Delhi. Trop Doct 2008;38(1):28-30.

18. Itha S, Kashyap R, Krishnani N, et al. Profile of liver involvement in dengue virus infection. Natl Med J India 2005;18(3):127-30. 